\title{
Enhanced and Synthetic Vision for Terminal Maneuvering Area NextGen Operations
}

\author{
Lynda J. Kramer*a , Randall E. Bailey, Kyle K. E. Ellis ${ }^{a}$, R. Michael Norman ${ }^{\mathrm{b}}$, Steven P. Williams ${ }^{\mathrm{a}}$, \\ Jarvis J. Arthur III ${ }^{\mathrm{a}}$, Kevin J. Shelton ${ }^{\mathrm{a}}$, and Lawrence J. Prinzel III ${ }^{\mathrm{a}}$ \\ ${ }^{a}$ NASA Langley Research Center, 24 W. Taylor Street, MS 152, Hampton, VA, USA 23681-2199; \\ ${ }^{\mathrm{b}}$ Boeing Research and Technology, MS 152, NASA LaRC, Hampton, VA, USA, 23681-2199
}

\begin{abstract}
Synthetic Vision Systems and Enhanced Flight Vision System (SVS/EFVS) technologies have the potential to provide additional margins of safety for aircrew performance and enable operational improvements for low visibility operations in the terminal area environment with equivalent efficiency as visual operations. To meet this potential, research is needed for effective technology development and implementation of regulatory and design guidance to support introduction and use of SVS/EFVS advanced cockpit vision technologies in Next Generation Air Transportation System (NextGen) operations.

A fixed-base pilot-in-the-loop simulation test was conducted at NASA Langley Research Center that evaluated the use of SVS/EFVS in NextGen low visibility ground (taxi) operations and approach/landing operations. Twelve crews flew approach and landing operations in a simulated NextGen Chicago O'Hare environment. Various scenarios tested the potential for EFVS for operations in visibility as low as $1000 \mathrm{ft}$ runway visibility range (RVR) and SVS to enable lower decision heights (DH) than can currently be flown today. Expanding the EFVS visual segment from DH to the runway in visibilities as low as 1000 RVR appears to be viable as touchdown performance was excellent without any workload penalties noted for the EFVS concept tested. A lower DH to $150 \mathrm{ft}$ and/or possibly reduced visibility minima by virtue of SVS equipage appears to be viable when implemented on a Head-Up Display, but the landing data suggests further study for head-down implementations.
\end{abstract}

Keywords: Synthetic Vision, Enhanced Vision, Enhanced Flight Vision System, Head-Up Display, Aviation Safety, Flight Deck Systems, All Weather Operations

\section{INTRODUCTION}

The U.S. air transportation system is undergoing a transformation to accommodate the movement of large numbers of people and goods in a safe, efficient, and reliable manner. ${ }^{1}$ One of the key capabilities envisioned to achieve this Next Generation Air Transportation System (NextGen) is the concept of equivalent visual operations (EVO). EVO is the capability to achieve the safety of current-day Visual Flight Rules (VFR) operations and maintain the operational tempos of VFR irrespective of the weather and visibility conditions.

One research challenge for EVO is the definition of required equipage on the aircraft and on the airport. With today's equipment and regulations, significant investment is required in on-board equipment for navigation, surveillance, and flight control and on the airport for precision guidance systems and approach lighting systems for "all-weather" landing capability. ${ }^{2}$ The levels of equipment redundancy, capability, maintenance, performance and crew training dramatically increase as landing visibility minima decrease. Synthetic Vision Systems and Enhanced Flight Vision Systems (SVS/EFVS) offer a means of providing EVO capability without significant airport infrastructure investment or training.

NASA Langley Research Center (NASA LaRC) and the Department of Transportation/Federal Aviation Administration (DOT/FAA) are jointly conducting collaborative research to ensure effective technology development and implementation of regulatory and design guidance to support introduction and use of SVS/EFVS advanced cockpit vision technologies in NextGen operations. These technologies have the potential to provide an additional margin of safety and aircrew performance to enable the implementation of operational improvements for low visibility surface, arrival, and departure operations in the terminal environment with equivalent efficiency as visual operations. This work 
builds from and extends the current operational use and certification of existing SVS/EFVS technologies to serve as building blocks toward all-weather, low visibility operations for NextGen.

\section{BACKGROUND}

SVS is a computer-generated image of the external scene topography, generated from aircraft attitude, high-precision navigation, and data of the terrain, obstacles, cultural features, and other required flight information. EFVS is an electronic means to provide a display (typically on a head-up display, or HUD) of the external scene by use of an imaging sensor, such as a Forward-Looking InfraRed (FLIR) or millimeter wave radar. Both SVS and EFVS are "vision-based" technologies intended to create, supplement, or enhance the natural vision of the pilot.

NASA and others have developed and shown SVS technologies that provide significant improvements in terrain awareness and reductions for the potential of Controlled-Flight-Into-Terrain incidents/accidents, ${ }^{3-5}$ improvements in flight technical error to meet Required Navigation Performance criteria, ${ }^{6,7}$ and improvements in situation awareness (SA) without concomitant increases in workload compared to current generation cockpit technologies. ${ }^{8-12}$ As such, SVS, often displayed on a Head-Down Display (HDD), is emerging as "standard equipage" for Part 23 and Part 25 business and general aviation aircraft flight decks even though, to date, no "operational credit" is obtained by SVS equipage.

EFVS capability on a HUD using FLIR sensor technology has also carved out a significant share of the business aircraft market and is growing in Part 121 operations. EFVS provides many of the same operational benefits as SVS technology, but it uses a direct view of the external environment, independent of the aircraft navigation solution or database. These differences, in part, enable operational credit by use of an approved EFVS. In 2004, Chapter 14 of the Code of Federal Regulations (CFR) Section $\S 91.175$ was amended such that operators conducting straight-in instrument approach procedures (in other than Category II or Category III operations) may now operate below the published Decision Altitude (DA), Decision Height (DH) or Minimum Descent Altitude (MDA) when using an approved EFVS shown on the pilot's HUD.

Synthetic and Enhanced Vision Systems (SEVS) technologies, such as SVS/EFVS in combination with HDD/HUD, form the basis for an electronic display of visual flight references (terrain, obstacles, and operations-critical navigational and situational references) on electronic cockpit display(s) for the flight crew, integrated with conformal symbology providing important situation, guidance, and/or command information as necessary and/or appropriate to enable all weather approach and landing operations. The primary reference for maneuvering the airplane is based on what the pilot sees through the SEVS, in lieu of or supplemental to the pilot's natural vision.

The key concept under the revisions to $\S 91.175$ is that an EFVS can be used in lieu of the required natural vision from the DA/DH/MDA to 100 feet (ft) height above the touchdown zone elevation (TDZE). Minimum aviation system performance standards are now available (RTCA DO-315 ${ }^{13}$ ) and an FAA Advisory Circular (AC 90-106 ${ }^{14}$ ) provides guidance for design and certification criteria of EFVS for operational credit. DO-315 also provides performance standards for SVS but with no additional operational credit. In other words, installing SVS does not change the airplane's existing operational capability or certification basis.

The emerging challenge for NextGen - and the subject of NASA research - is to develop performance-based standards for SEVS technologies that create EVO and beyond. The first part of this challenge is the development of performancebased standards expanding the current operational approvals of SVS/EFVS.

The design and use of SEVS technology is integrally tied to the operating rules for landing and take-off under Instrument Flight Rules (IFR) (14 CFR §91.175). For EFVS operations, §91.175 was modified such that, to operate below the $\mathrm{DA} / \mathrm{DH}$ or MDA, certain visual references must be seen using the EFVS to continue the descent below the published DA/DH or MDA (see 14 CFR §91.175). No lower than $100 \mathrm{ft}$ height above the TDZE, the visual references that positively identify the runway of intended landing must be distinctly visible and identifiable using natural vision.

The FAA has started a rulemaking project to expand operational credit for EFVS beyond what is currently authorized by the regulations (under 14 CFR $\$ 91.175$ ). DO-315 $\mathrm{A}^{15}$ was drafted to establish performance standards in concert with this rulemaking project. Minimum performance standards are now published for EFVS operations through the approach to touchdown in visibility as low as $1000 \mathrm{ft}$ runway visual range (RVR) by sole use of an approved EFVS in lieu of natural vision. Simply stated, the visual segment of the approach can now be accomplished by using either enhanced flight visibility or natural vision. Past NASA research supports the viability of this expanded EFVS visual segment that 
showed that using an EFVS through touchdown resulted in excellent localizer tracking performance and an improvement in glideslope tracking performance. ${ }^{16}$

The joint RTCA SC-213/EUROCAE WG 79 committee is also working on minimum performance standards for possible operational credit for SVS (under DO-315B, in RTCA Final Review and Comment process). Unlike EFVS, the possible path for operational credit is not through revision of 14 CFR $\S 91.175$, but is based on FAA Order 8400.13 ("Procedures for the Evaluation and Approval of Facilities for Special Authorization Category I Operations and All Category II and III Operations"). Specifically, DO-315B establishes performance standards for a SVS enabling lower than standard Category I minima or a reduction in the required minimum visibility. These proposed DO-315B performance standards for SVS operational credit do not require the use of a HUD.

A fixed-base experiment was conducted to evaluate selected elements of the proposed performance standards for expanded EFVS and SVS operational credits. Specifically, the high-level objectives of this simulation test were to:

- Evaluate the operational feasibility, pilot workload, and pilot acceptability of conducting a straight-in instrument approach procedure with published vertical guidance using EFVS (i.e., FLIR imagery on a HUD) for the approach, landing, roll-out and turn-off in weather and visibility as low as $1000 \mathrm{ft} \mathrm{RVR.}$

- Evaluate the operational feasibility, pilot workload, and pilot acceptability of conducting a straight-in instrument approach to a $150 \mathrm{ft} \mathrm{DA} / \mathrm{DH}$ procedure with published vertical guidance using SVS (displayed either head-down or head-up) and to transition to natural out-the-window (OTW) visual conditions for landing in weather and visibility as low as $1400 \mathrm{ft}$ RVR.

In addition, the following test objectives were evaluated in this experiment, but are not reported in this paper:

- The influence of selected DO-315 minimum performance standards items for EFVS (e.g. EFVS failure at $50 \mathrm{ft}$ above field level (AFL) in varying RVR conditions) and SVS (e.g., un-alerted navigational position errors at Wide Area Augmentation System horizontal alert limit and vertical alert limit values)

- Evaluation of time required, accuracy, and pilot workload associated with recognizing and reacting to potential ground collisions or conflicts with other aircraft, vehicles and obstructions across a range of visibility and lighting conditions using an EFVS and SVS

- Using single and dual pilot operations.

- With and without the cockpit display of traffic information (CDTI).

Further, eye gaze data were collected to quantify the pilot's visual attention when flying the instrument segment, the transition from instrument to visual, and during the visual segment. Analyses of these data are ongoing and not reported here.

\section{METHODOLOGY}

\subsection{Subjects}

Twenty-four pilots served as participants for the research, representing twelve flight crews. Ten crews flew for major U.S. air carriers and were paired by airline to ensure crew coordination and cohesion with regard to terminal and surface operational procedures. The other crews were business aircraft operators, flying Gulfstream G-V or G450 aircraft equipped with EFVS and SVS. The Captains had an average of over 14,661 flight hours with 21 years of commercial flying. The First Officers had an average of over 10,648 flight hours with 14 years of commercial experience. The Captains were recruited on the basis of HUD experience (at least 100 hours), with preference given to pilots with Enhanced Vision (EV)/EFVS experience. All pilots were required to hold an Airline Transport Pilot rating.

The Captain was the designated pilot-flying (PF) throughout all the trials and the First Officer served as the pilot-notflying (PNF) or monitoring pilot.

\subsection{Simulation Facility}

This research was conducted in the Research Flight Deck (RFD) simulator at NASA LaRC (Figure 1). The RFD is configured with four 10.5-inch Vertical (V) by 13.25-inch Horizontal (H), 1280x1024 pixel resolution color displays, 
tiled across the instrument panel. Also, the RFD includes a HUD on the left side of the cab, Mode Control Panel, Flight Management System (FMS), and two Electronic Flight Bags (EFBs) (Figure 1).

The full-mission RFD simulates a Boeing B-757-200 aircraft, albeit controlled through sidestick inceptors. The cab is populated with flight instrumentation and pilot controls, including the overhead subsystem panels, to replicate the B-757.

A collimated OTW scene is produced by an Evans and Sutherland Image Generator graphics system providing approximately $200^{\circ} \mathrm{H}$ by $40^{\circ} \mathrm{V}$ field-of-view (FOV) at 26 pixels per degree.

The sidestick inceptor force gradients and deflection characteristics mimic the Airbus 320 aircraft. ${ }^{17}$ A parabolic shaping gearing was used between the normalized stick deflection of the sidesticks and the elevator and aileron commands of the B-757 aircraft. The parabolic shaping provided acceptable handling characteristics for the approach, landing, and departure tasks. The pilot and co-pilot inceptors are directly linked as if mechanically connected.

The auto-throttle system backdrives the throttle handles to directly reflect the power setting commanded to the engines. Take-off, go-around (TOGA) buttons and autothrottle disconnect buttons are placed on the throttle handles.

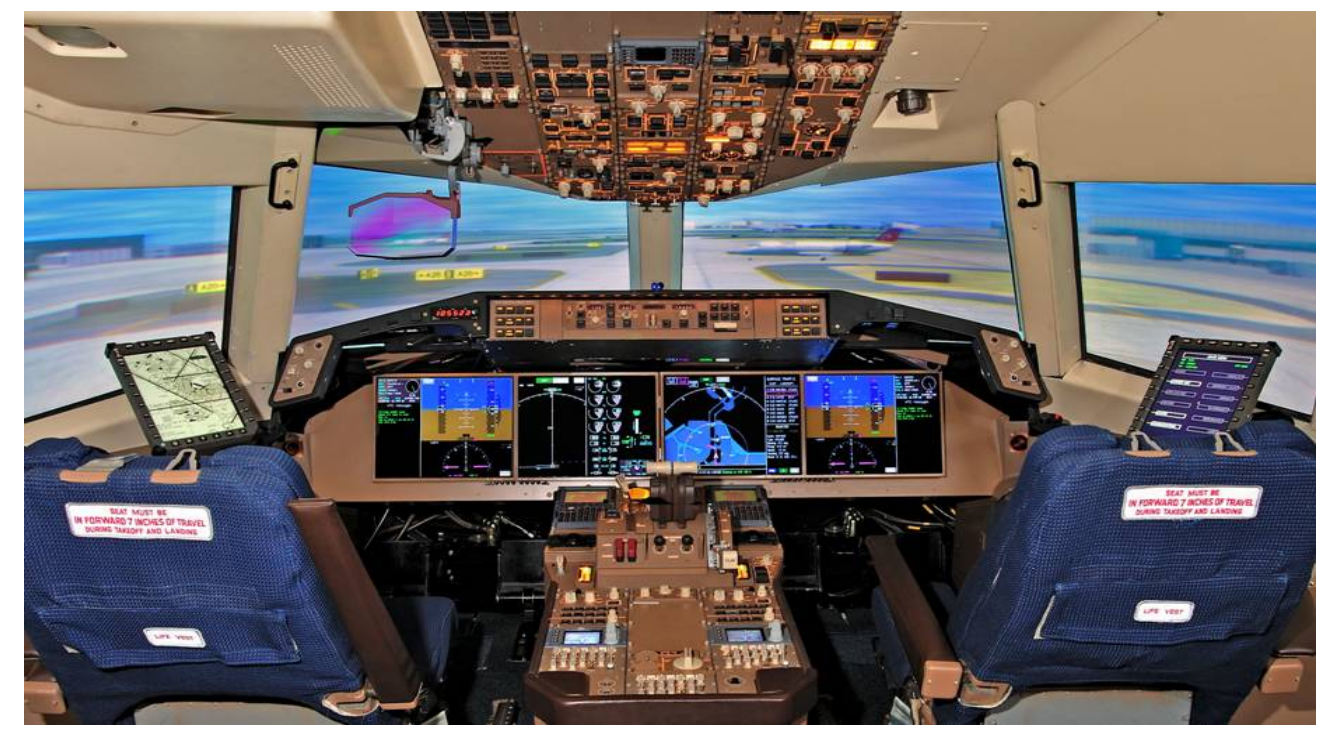

Figure 1. Research Flight Deck Simulator with HUD, Head-down Instrument Panel and EFB

\subsubsection{Simulator Database}

Operations were simulated at Chicago O'Hare International Airport (FAA identifier: ORD). The simulation was built around FAA source data for ORD, valid from 11 March 2010 to 8 April 2010. These data were used to develop all flight plans, scenarios, approach paths, and OTW, synthetic vision (SV) and EV databases.

Day simulations were flown, with the weather tailored to create the desired visibility conditions.

Approaches were flown only to runways with Medium intensity Approach Lighting System with Runway alignment indicator lights (MALSR) installed. Testing included an experimental variation of touchdown zone and centerline (TDZ/CL) lights (on and off), where operations with TDZ/CL lights were conducted on ORD Runway 9R; otherwise, ORD Runways $4 \mathrm{R}, 22 \mathrm{~L}$, or $22 \mathrm{R}$ were used. All runways included high intensity runway lights and serviceable centerline and surface markings. Airport lighting was drawn using calligraphics.

\subsection{2 $\quad$ Audio Effects}

Altitude call-outs were played over the flight deck speakers. The automatic altitude calls-out started at "500 feet" when the aircraft was $500 \mathrm{ft}$ above the TDZE. The "approaching minimums" and "minimums" call-outs were generated at 100 $\mathrm{ft}$ above and at the planned DA/DH for a given run. 
Flare "prompts" in the form of additional altitude call-outs were used on all runs ("100," "50," "40," "30," "20," and " $10 "$ at the corresponding radar altitudes in feet).

\subsubsection{Head-Down Displays}

Figure 1 shows the simulator's four main instrument panel displays: a) PF left display, including primary flight display (PFD); b) PF right display including navigation display (ND); c) PNF left display, including ND; and, d) PNF right display, including PFD. The format and content of these displays were varied experimentally as described below.

\subsection{4 $\quad$ Head-Up Display}

The RFD is equipped with a Rockwell-Collins HGS-4000 HUD. The HUD is collimated and subtends approximately $26^{\circ} \mathrm{H}$ by $21^{\circ} \mathrm{V}$ FOV. The HUD projects the imagery from a Cathode Ray Tube source in a stroke-and-raster format (Figure 2). The raster input to the HUD was either a SV or EV source imagery in an RS-343 format. The stroke symbology format was a modified version of the HGS Primary mode format. The stroke symbology included a runway outline (edgelines) which was conformally drawn until $50 \mathrm{ft}$ AFL, a flight path angle reference cue and a flight-path referenced guidance cue. The guidance cue was driven by the B-757 flight director. In addition, a HUD flare cue, consisting of a flare "prompt," was provided where, at $50 \mathrm{ft}$ AFL, two "plus" signs flashed above the flight path marker.

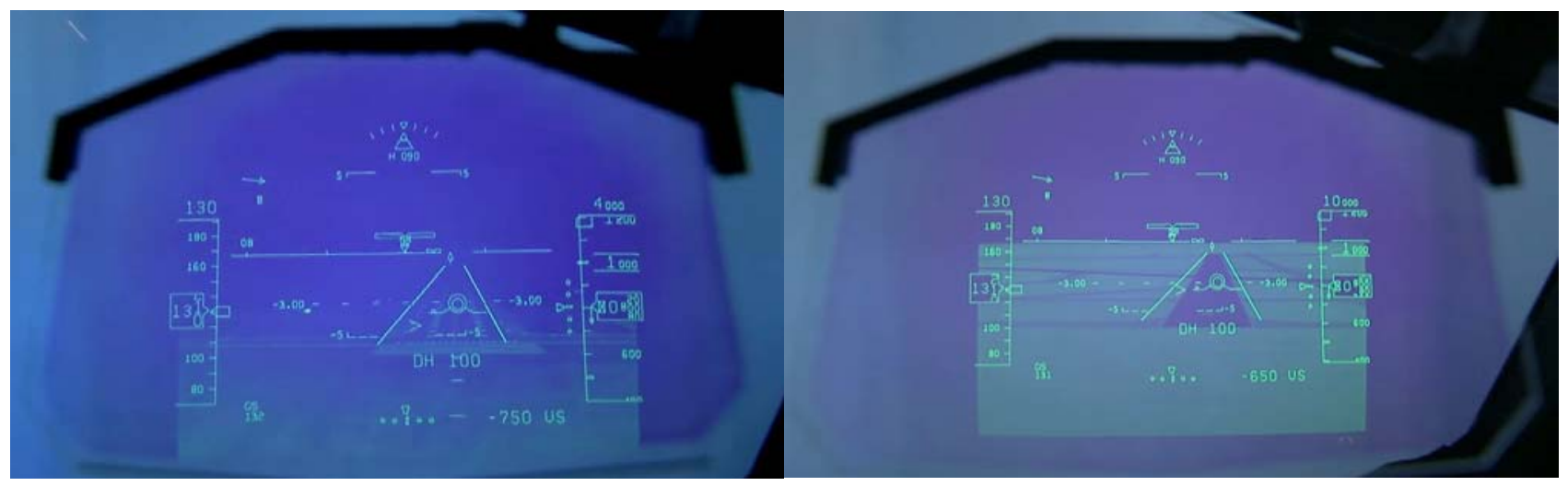

Figure 2. EFVS HUD (left) and SVS HUD (right) Symbology Format

The PF had independent controls to adjust the stroke symbology brightness and the raster imagery brightness and contrast. The PF also had a declutter control, implemented as a four-button castle switch on the pilot's sidestick. The four "declutter" states available to the PF were: 1) Declutter All (no symbology or imagery); 2) Symbology (Stroke) Toggle on/off; 3) Imagery (Raster) Toggle on/off; and 4 Display All (both symbology and imagery).

The HUD was stowed when not being used to avoid any confounding from the HUD being in place during "non-HUD" runs.

\subsection{SV Simulations}

A SV database was developed by NASA starting from the OTW database, generally following the standards from DO315B (draft). The database used a 1 arc-second Digital Elevation Model (DEM) of a $110.25 \mathrm{~nm}$ (East-West) by 145.6 (North-South) $\mathrm{nm}$ area centered around ORD. The DEM was draped with an elevation-based coloration texturing.

Each ORD runway was modeled as an asphalt-colored polygon using the threshold data and runway widths. Threshold lines, edgelines, and runway numbers were added.

The intended landing runway (as selected through the FMS prior to run initiation) was denoted on the primary display concept being evaluated, either as a conformal magenta outline on the head-down PFD depiction, or an 8000 x $200 \mathrm{ft}$ outline (shown as edgelines) on the HUD.

Because the test was confined to low altitude approach, landing, and surface operations at ORD, obstacles would not create a significant visual cue. Therefore, obstacles were not included or marked in the SV depiction. 
The SVS-PFD symbology mirrored the HUD using conformal depictions for the flight path marker, single cue flight path-referenced guidance symbology, and flight path angle reference cue. Other required Primary Flight Reference information was also drawn (e.g., airspeed, altitude, and raw data deviations).

Several SV-specific items are called out to note:

- When drawn on the HUD, the SV database terrain texturing and coloration was slightly changed to improve its visual perception primarily by specific coloration for conversion into a gray-scale format.

- The SV depiction was always drawn in a heading-up format. Any crosswind was evident by conformal lateral positioning of the flight path marker. However, the flight path marker and guidance cue were limited and displayed as ghosted representations if their conformal positions exceeded pre-determined values.

\subsection{EV Simulation}

The EV real-time simulation is created by the Evans and Sutherland EPX physics-based sensor simulation. The ORD database was instantiated with material code properties. From this database, an IR sensor simulation, interacting with this material-coded database and the simulated weather conditions, created the desired test experimental conditions.

The EV simulation mimicked the performance of a short-wave/mid-wave FLIR, using a $\sim 1.0$ to 5.0 micron wavelength detector. The nominal enhanced visibility was approximately $2400 \mathrm{ft}$ for this experiment.

The eye point reference for the EV simulation was placed $5 \mathrm{ft}$ below the pilot design eye reference point, but otherwise properly boresighted (i.e., angular alignment) to the aircraft. In the B-757, the pilot is approximately $20 \mathrm{ft}$ above the ground during surface operations. This EV eye point reference/parallax error generates $2.5 \mathrm{mrad}$ error to a point located $2000 \mathrm{ft}$ away - approximately half of the accuracy budget of the EFVS per current DO-315 accuracy requirements. ${ }^{13}$

\subsection{Navigational Performance Variations}

Variations in navigational accuracy were simulated on each run, bounding $\pm 12 \mathrm{ft}$ vertical and $\pm 12 \mathrm{ft}$ horizontal deviations from the true position. This effect was added for realism in positioning system accuracy. The selected inaccuracies were randomly varied across each subject's test matrix and were held constant during a run.

\subsection{Crew Display Concepts}

Two head-down flight display concepts and three head-up flight display concepts were evaluated by the crews while flying approaches, landings, and surface operations to Runways 4R, 9R, 22L or 22R at ORD.

\subsubsection{Head-Down Flight Display Concepts}

The two HDD concepts (referred to as the Baseline HDD and SVS HDD) are shown in Figure 3, differing from each other only in the absence or presence of SVS on the PFD. The HUD was stowed during HDD evaluations.

The SVS on the PFD portrayed a $33^{\circ} \mathrm{V}$ x $44^{\circ} \mathrm{H}$ field-of-regard. Assuming a 25 inch distance from the Design Eye Reference Point to the display, the SVS concept had a minification factor of approximately 2.1 for the PF. The PF left display also had a datalink message area and Horizontal Situation Indicator (HSI). The PNF right display showed a quad-view of flight information: a PFD (upper left); HSI (lower left); FLIR repeater or blank area (upper right); and datalink message area (lower right). The upper right area of the quad-display was blank for baseline and SVS HDD evaluations.

The PF (right display) and PNF (left display) NDs always showed flight traffic and navigational information in the airborne mode (see Airborne Modes on Figure 3). The PF and PNF NDs transitioned to a moving map mode when on the ground and groundspeed less than 100 knots (see Surface Modes on Figure 3). The PNF ND included a runway inset view in both airborne and moving map modes.

The surface moving map and the runway inset views always showed their respective images of the airport and intended landing runway, but traffic icons (i.e., cockpit display of traffic information, or CDTI) were only drawn when being experimentally evaluated. These experimental variations (e.g., the presence and absence of CDTI) were conducted to test the time required, accurate identification, and pilot workload associated with recognizing and reacting to potential ground collisions or conflicts with other aircraft. 


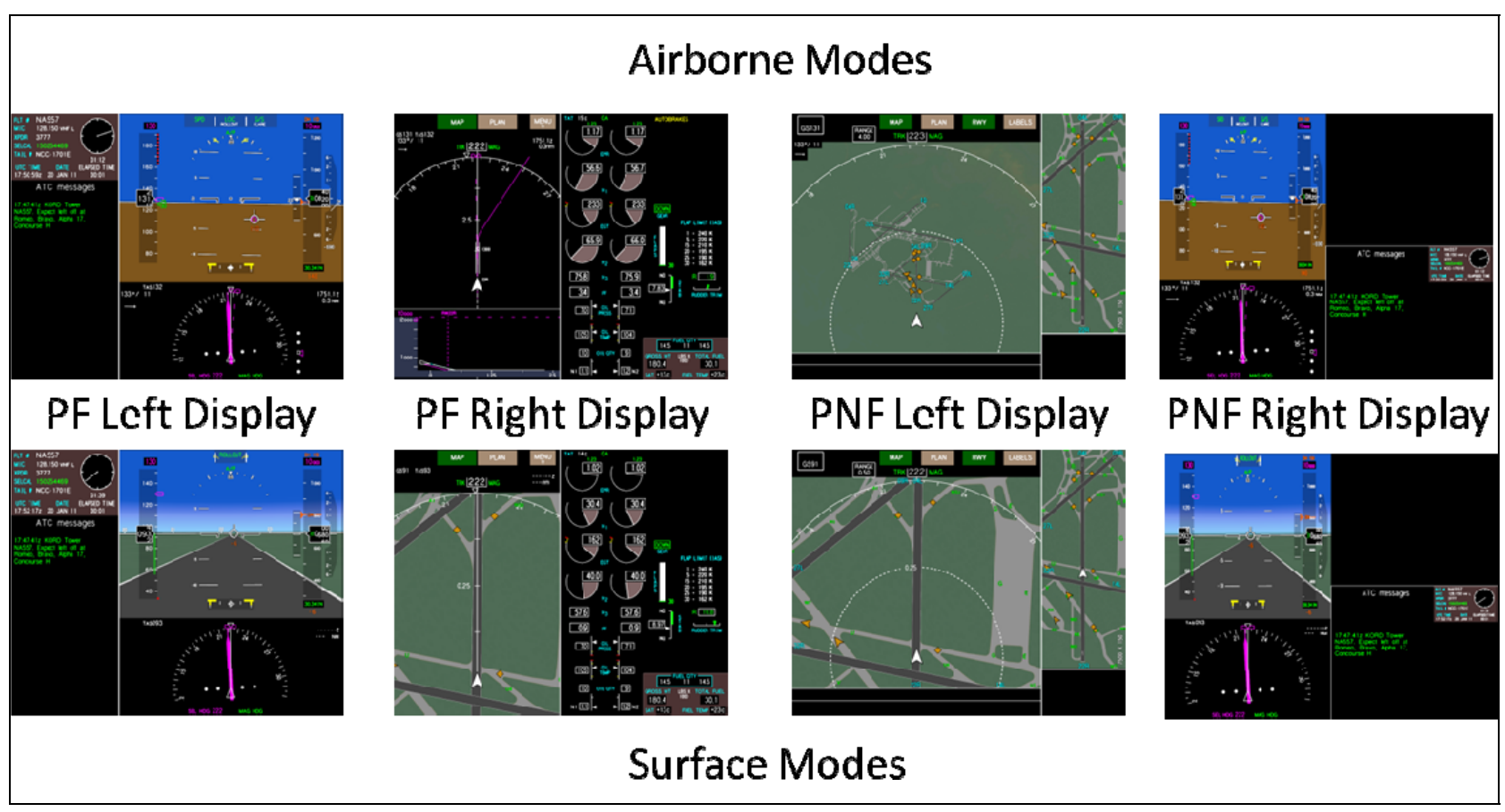

Figure 3. Head-Down Display (HDD) Concepts: Baseline HDD on top and SVS HDD on bottom

\subsubsection{Head-Up Flight Display Concepts}

The three HUD concepts (referred to as the Baseline HUD, SVS HUD and EFVS) were tested, differing from each other only in the absence or presence of imagery (SV or FLIR) on the PF HUD.

The Baseline HDD (i.e., no SVS) concept was displayed during these runs. The PNF (head-down) right display showed FLIR imagery in the upper right corner of the quad-view for EFVS runs and was blank (black in color) for Baseline and SVS HUD runs. Figure 2 (in the left-side view) shows the EFVS display concept with symbology and FLIR imagery.

\subsection{Evaluation Task}

The evaluation task was a straight-in Instrument Landing System (ILS) approach with a 3 degree descent angle to one of 4 ORD runways $(4 \mathrm{R}, 9 \mathrm{R}, 22 \mathrm{R}$, or $22 \mathrm{~L})$. For each run, the approach started 3 nautical miles $(\mathrm{nm})$ from the runway threshold. The weather consisted of low to moderate winds with either 10 knot headwind, 10 knot tailwind, 7.5 knot crosswind, or $15 \mathrm{knot}$ crosswind, light turbulence (root-mean-square (rms) of $1 \mathrm{ft} / \mathrm{sec}$ ), and varying OTW visibility levels (1800 ft, $1400 \mathrm{ft}$, or $1000 \mathrm{ft}$ RVR). When used experimentally, the FLIR visibility was $2400 \mathrm{RVR}$. The PF handflew the approach from the left seat with the auto-throttle set to "speed-hold" at the approach speed of 130 knots indicated airspeed. The auto-throttle automatically reduced to idle thrust at $35 \mathrm{ft}$ above ground level (AGL) for landing. The run was terminated once the PF completed the landing, roll-out and turnoff or upon go-around initiation. The aircraft was configured to land prior to each run (landing gear down and flaps 30 degrees).

The PFs were instructed to fly the aircraft as if there were passengers aboard, track the approach path, and land within the touchdown zone with an acceptable sink rate. After landing, they were to capture the centerline and exit at the expected taxiway at a speed to 5 to 15 knots at the 90 degree exits or 30 knots at the high-speed exits. They were also instructed to initiate a go-around if the landing was not safe or there were any safety concerns during the approach.

\subsection{Crew Procedures}

The crew was trained in 'monitored approach' crew procedures. The PF flew the approach using the HUD or HDD as the primary flight reference. The PNF monitored using the available HDD information, including a FLIR repeater (when EFVS was flown), and the OTW scene and assisted the PF as appropriate and necessary. There was no transfer of control from the PF to PNF (or vice versa). 
To facilitate comparison between baseline conditions (i.e., no SVS or EFVS installed) and SVS/EFVS configurations, crew procedures were standardized and trained.

\subsubsection{Baseline and SVS Procedures}

The procedures for the baseline (i.e., no SVS or EFVS installed) and SVS configurations were identical and followed normal crew instrument approach procedures. One of the intended functions of the SVS is to improve the pilot's ability to conduct the instrument portion of the approach - not to enable descent below the published DA/DH. Therefore, no change in crew procedures would be expected.

\subsubsection{EFVS Procedures}

The EFVS procedures were built around common practice in current EFVS operations and FAA requirements (14 CFR $\S 91.175$ (1)) but extended to emphasize that to descend below the DA/DH and to descend below $100 \mathrm{ft}$ height above the TDZE depended upon the PF being able to recognize and identify the required visual references, using EFVS.

\subsection{Experiment Matrix}

The primary experiment test matrix aligned three visibility conditions against five SEVS configurations (combinations of vision systems and displays) as shown in Table 1.

Table 1. Experiment Matrix

\begin{tabular}{|c|c|c|c|c|}
\hline \multirow[b]{2}{*}{ Display } & \multirow[b]{2}{*}{$\begin{array}{l}\text { Vision } \\
\text { System }\end{array}$} & \multicolumn{3}{|c|}{ Visibility } \\
\hline & & 1800 RVR & 1400 RVR & 1000 RVR \\
\hline \multirow[t]{3}{*}{ HUD } & None & & $\checkmark$ & \\
\hline & SVS & & $\checkmark$ & $\checkmark$ \\
\hline & EFVS & & $\checkmark$ & $\checkmark$ \\
\hline \multirow[t]{2}{*}{ HDD } & None & $\checkmark *$ & $\checkmark$ & \\
\hline & SVS & $\checkmark$ & $\checkmark$ & \\
\hline
\end{tabular}

* $200 \mathrm{ft}$ DA; All others $150 \mathrm{ft} \mathrm{DH}$

Wind variations were balanced across the experiment matrix for each crew/pilot to evenly distribute the conditions across the configurations. Thus, wind effects were tested but not in a 'within subjects' variation. It was assumed that left and right crosswinds could be interchanged without affecting any experimental results.

\subsection{Measures}

During each approach and landing run, path error, pilot control inputs, and touchdown performance (sink rate and speed at touchdown, distance fore or aft of touchdown zone, and distance left or right of centerline) were measured for analysis. During taxi operations, centerline tracking and taxi speed were measured.

After each run, pilots completed the AFFTC Workload Estimate Scale. ${ }^{18}$ After data collection was completed, pilots were administered two paired comparison tests: the Situation Awareness - Subjective Workload Dominance (SASWORD $)^{20}$ technique and one on Traffic Awareness evaluating CDTI formats tested.

\subsection{Test Conduct}

The subjects were given a one-hour briefing describing the experiment, HUD and HDD concepts, crew procedures, and evaluation tasks. The test purpose was described to the test subjects as "evaluating the potential use of EFVS and SVS for reduced landing weather minima and the influence of CDTI for NextGen operations."

After the briefing, a 1.5 hour training session in the RFD was conducted to familiarize the subjects with the aircraft handling qualities, display symbologies, pilot procedures, and controls. In particular, in-simulator training highlighted the crew procedures for EFVS and SVS operations and landing performance. Landing performance was planned as one of the performance parameters used to assess the efficacy of the SEVS experimental variations. However, none of the pilots were familiar with the handling characteristics of the RFD simulator (a sidestick-equipped B-757). To accommodate this disparity, each PF was trained to an acceptable standard of approach and landing performance. 
In Table 2, touchdown performance criteria are shown. After each training run, a landing performance "scorecard" against these criteria was displayed for feedback. The pilots were asked to meet the desired performance criteria. Training concluded once the pilots demonstrated repeatable desired landing performance, albeit with an occasional adequate performance score. If the acceptable performance criteria were met, they landed within the touchdown zone with acceptable sink rates.

The training was flown in varying OTW visibility from visual conditions down to $1000 \mathrm{ft} \mathrm{RVR}$. Similarly, EFVS visibility ranged from unlimited down to $1000 \mathrm{ft}$. The training emphasized that they must always remain safe and if they felt unsafe conditions exist, the necessary precautions, including a go-around, should be executed immediately.

Table 2. Touchdown Performance Scorecard

\begin{tabular}{|l|l|l|l|}
\hline Performance Value & Desired & Adequate & Not Adequate \\
\hline \hline $\begin{array}{l}\text { Lateral Distance from } \\
\text { Centerline }\end{array}$ & Within $+/-27 \mathrm{ft}$ & $\begin{array}{l}\text { Between }+27 \text { and }+58 \mathrm{ft} \text { or } \\
\text { Between }-27 \text { and }-58 \mathrm{ft}\end{array}$ & $>+/-58 \mathrm{ft}$ \\
\hline $\begin{array}{l}\text { Longitudinal Distance from } \\
\text { Threshold }\end{array}$ & Between 750 to $2250 \mathrm{ft}$ & $\begin{array}{l}\text { Between } 200 \& 750 \mathrm{ft} \text { or } \\
\text { Between } 2250 \& 2700 \mathrm{ft}\end{array}$ & $<200$ or $>2700 \mathrm{ft}$ \\
\hline Sink rate & Between 0 to $6 \mathrm{ft} / \mathrm{sec}$ & Between 6 to $10 \mathrm{ft} / \mathrm{sec}$ & $>10 \mathrm{ft} / \mathrm{sec}$ \\
\hline Airspeed (kts) & Between $\mathrm{V}_{\text {ref }}-5$ to $\mathrm{V}_{\text {ref }}+5$ & Between $\mathrm{V}_{\text {ref }}-5$ to $\mathrm{V}_{\text {ref }}-15$ & $<\mathrm{V}_{\text {ref }}-15$ or $>\mathrm{V}_{\text {ref }}+5$ \\
\hline
\end{tabular}

$\mathrm{V}_{\text {ref }}+5$ is the approach speed in table above

\section{RESULTS}

\subsection{Landing Performance}

Touchdown statistics were used to evaluate how effectively the pilots could land with the different SEVS display concepts and how well the crews met the touchdown performance criteria (Table 2) to which they had been trained.

SEVS landing performance was evaluated by using a fixed $1400 \mathrm{ft} R V R / 150 \mathrm{ft} \mathrm{DH}$ and conducting ANOVA (Analysis of Variance) analyses for the factors of display concept (Baseline HUD, SVS HUD, EFVS, Baseline HDD, and SVS HDD) and TDZ/CL lights (on, off) on touchdown longitudinal position, lateral position, and sink rate. EFVS-specific landing performance was evaluated by conducting ANOVAs for OTW visibility (1000 ft RVR, $1400 \mathrm{ft}$ RVR) and TDZ/CL lights (on, off) on these same touchdown measures. Independent ANOVAs were conducted for SVS HUD and SVS HDD landing performance for the factors of OTW visibility and TDZ/CL lights.

Finally, the ability to meet FAA AC $120-28 \mathrm{D}^{19}$ performance-based landing standards were assessed across the display types and TDZ/CL light configurations tested.

\subsubsection{Touchdown Statistics}

In Table 3, the touchdown (T/D) data (mean, standard deviation, minimum value, and maximum value) are shown, broken out by display concept and TDZ/CL light configuration, for the fixed 1400 RVR OTW and $150 \mathrm{ft}$ DH testing condition. Also provided in Table 3 are the number of runs that resulted in a TOGA and the total number of runs for the combinations of display concept and TDZ/CL light configurations tested.

The data show that:

- The decision by the pilots to safely continue the descent below the DH (150 ft) to landing depended upon the SEVS concept and the location of the information (head-up or head-down).

o $\quad 92 \%$ (22 out of 24 runs) of the Baseline HUD runs were flown to a landing, with no apparent influence of the TDZ/CL lighting condition.

o $100 \%$ (24 out of 24 runs) of the EFVS HUD runs were flown to a landing (i.e., no TOGAs), irrespective of the TDZ/CL lights.

o $83 \%$ (20 out of 24 runs) of the SVS HUD approaches were flown to landing, with no apparent influence of the TDZ/CL lighting condition. 
o For the head-down condition, $83 \%$ (20 out of 24 runs) of the SVS HDD approaches were flown to landing, with more TOGAs flown with the TDZ/CL lighting condition.

o Conversely, without SVS, crews successfully completed a landing only $50 \%$ of the time when flying the Baseline HDD concept to runways without TDZ/CL lights compared to $92 \%$ of the time (11 out of 12 runs) to a runway with TDZ/CL lights.

- The mean lateral position from centerline was within the "desired" T/D scorecard performance level (within \pm $27 \mathrm{ft}$ ) for all display concepts at $1400 \mathrm{RVR}$, irrespective of the TDZ/CL lights.

- The mean T/D sink rate was only within the "adequate" performance level (between 6 to $10 \mathrm{ft} / \mathrm{sec}$ ) for all display concepts at $1400 \mathrm{RVR}$, irrespective of the TDZ/CL lights.

- The mean longitudinal T/D position performance varied by SEVS condition and the presence/absence of TDZ/CL lights:

o The mean longitudinal T/D position performance was within the "desired" performance level (between 750 to $2250 \mathrm{ft}$ from threshold) for all EFVS HUD runs, irrespective of the TDZ/CL lights.

o The mean longitudinal T/D position performance was within the "desired" performance level (between 750 to $2250 \mathrm{ft}$ from threshold) for all HUD SVS runs, irrespective of the TDZ/CL lights.

o Although $92 \%$ of the Baseline HUD runs were flown to a landing, irrespective of the TDZ and CL lighting condition, only those flown to a runway with TDZ/CL lights met "desired" performance levels. The ones flown to runways without TDZ/CL lights only met "adequate" performance levels (between $200 \& 750 \mathrm{ft}$ or between 2250 and $2700 \mathrm{ft}$ from threshold) for longitudinal T/D position.

- The mean longitudinal T/D position performance was within the "desired" performance level (between 750 to $2250 \mathrm{ft}$ from threshold) for SVS HDD runs only with TDZ and CL lights. The ones flown to runways without TDZ/CL lights only met "adequate" performance levels for longitudinal T/D position.

o All Baseline HDD runs met the "desired" level of performance for longitudinal T/D position, irrespective of the TDZ and CL lights. However, the presence of TDZ/CL lights had a profound effect on whether a landing was attempted - only $50 \%$ of approaches to a runway without TDZ/CL lights were flown to landing compared to $92 \%$ of the time to a runway with TDZ/CL lights.

In Table 4, the touchdown data are shown for the $1000 \mathrm{ft}$ RVR HUD runs and $1800 \mathrm{ft}$ RVR SVS HDD runs, broken out by TDZ/CL light configuration. Note that one landing for the SVS HDD concept, $1800 \mathrm{RVR} / 150 \mathrm{ft} \mathrm{DH}$, with TDZ/CL lights landed $50 \mathrm{ft}$ short of the runway threshold (shown in red, bold font in Table 4 for emphasis). These data are included in the statistical analysis but the significance of this event cannot be ignored.

Similar to the $1400 \mathrm{ft}$ RVR values, Table 4 shows that the mean values for the lateral T/D distance met the "desired" levels for the 1000 RVR HUD runs and 1800 RVR HDD configurations. The mean values for the T/D sink rate only met the "adequate" levels for the 1000 RVR HUD runs and 1800 RVR HDD configurations. Also, like the $1400 \mathrm{ft}$ RVR EFVS runs, there were no go-arounds for any of the $1000 \mathrm{ft}$ RVR EFVS HUD approaches and all met the "desired" longitudinal T/D performance criteria.

The data show the influence of SVS/EFVS on the pilots' decision to safely continue the descent below the DH (150 ft) to landing. For the EFVS HUD runs, all approaches were flown to a landing even as the OTW visibility was reduced to $1000 \mathrm{ft} \mathrm{RVR}$. For the SVS HUD concepts, $71 \%$ (17 out of 24 runs) of the $1000 \mathrm{ft}$ RVR runs were flown to touchdown, irrespective of the TDZ and CL lights. For the SVS HDD concept, 96\% (23 of the 24 runs) of the $1800 \mathrm{ft}$ RVR runs were flown to landing.

Across almost every case, sink rates outside of the "acceptable" performance criteria were evident (as seen in the max sink rate values in Tables 3 and 4). 
Table 3. Touchdown Statistics for 1400 RVR and $150 \mathrm{ft}$ DH Runs

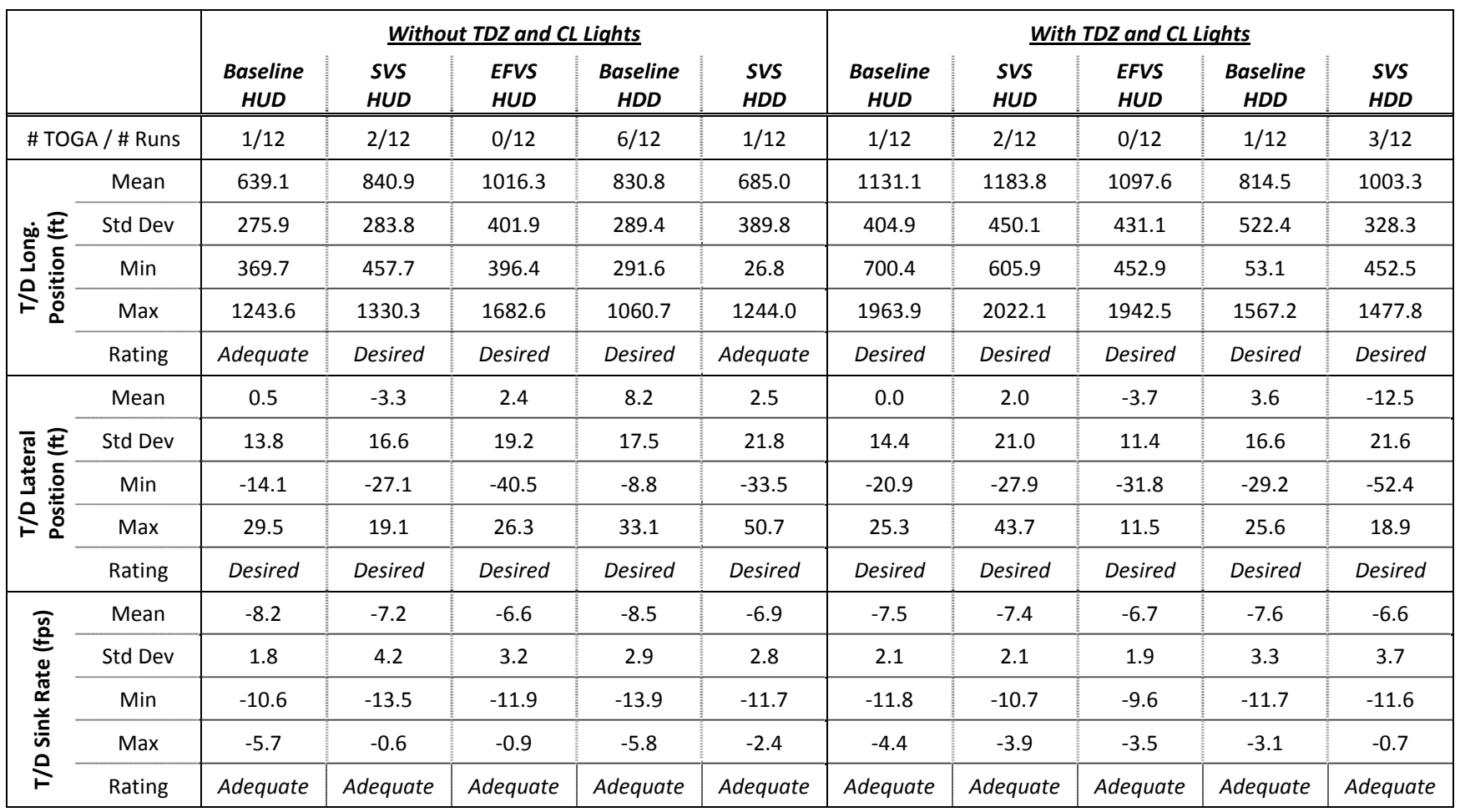

Table 4. Touchdown Statistics for 1000 RVR and 1800 RVR Runs

\begin{tabular}{|c|c|c|c|c|c|c|c|}
\hline & & \multicolumn{3}{|c|}{ Without TDZ and CL Lights } & \multicolumn{3}{|c|}{ With TDZ and CL Lights } \\
\hline & & $\begin{array}{l}\text { EFVS } \\
\text { HUD }\end{array}$ & $\begin{array}{l}\text { SVS } \\
\text { HUD }\end{array}$ & $\begin{array}{l}\text { SVS } \\
H D D\end{array}$ & $\begin{array}{l}\text { EFVS } \\
\text { HUD }\end{array}$ & $\begin{array}{l}\text { SVS } \\
H U D\end{array}$ & $\begin{array}{l}S V S \\
H D D\end{array}$ \\
\hline & & 1000 RVR & 1000 RVR & 1800 RVR & $1000 R V R$ & 1000 RVR & 1800 RVR \\
\hline \# TOC & A / \# Runs & $0 / 12$ & $4 / 12$ & $0 / 12$ & $0 / 11$ & $3 / 12$ & $1 / 12$ \\
\hline \multirow{5}{*}{ 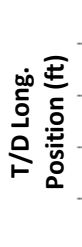 } & Mean & 798.6 & 742.0 & 835.1 & 1026.3 & 770.8 & 944.0 \\
\hline & Std Dev & 358.5 & 496.6 & 397.2 & 288.9 & 157.7 & 546.1 \\
\hline & Min & 430.0 & 229.9 & 341.1 & 706.9 & 462.5 & -50.0 \\
\hline & Max & 1662.7 & 1814.2 & 1711.7 & 1635.4 & 948.9 & 2146.5 \\
\hline & Rating & Desired & Adequate & Desired & Desired & Desired & Desired \\
\hline \multirow{5}{*}{ 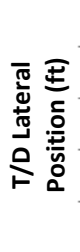 } & Mean & -1.2 & -3.3 & -3.5 & 0.6 & 5.4 & 5.2 \\
\hline & Std Dev & 14.7 & 18.2 & 19.1 & 12.7 & 11.6 & 11.0 \\
\hline & Min & -30.8 & -32.4 & -33.4 & -16.0 & -15.2 & 19.7 \\
\hline & Max & 25.9 & 19.2 & 26.8 & 19.7 & 20.3 & -16.6 \\
\hline & Rating & Desired & Desired & Desired & Desired & Desired & Desired \\
\hline \multirow{5}{*}{ 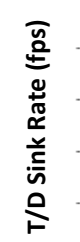 } & Mean & -7.7 & -6.8 & -7.0 & -7.6 & -6.4 & -6.8 \\
\hline & Std Dev & 3.7 & 2.4 & 3.2 & 3.0 & 2.0 & 3.1 \\
\hline & Min & -15.8 & -10.3 & -12.5 & -12.7 & -9.9 & -11.4 \\
\hline & Max & -3.4 & -3.4 & -1.8 & -4.5 & -4.3 & -2.6 \\
\hline & Rating & Adequate & Adequate & Adequate & Adequate & Adequate & Adequate \\
\hline
\end{tabular}




\subsection{2 $\quad$ ANOVA Analyses on Touchdown performance}

The touchdown data were analyzed for statistical significant differences.

Fixed $1400 \mathrm{RVR}$ OTW/150 ft DH runs: ANOVA analyses revealed that the presence of TDZ/CL lights had a highly significant effect $(\mathrm{F}(1,93)=9.57, \mathrm{p}=0.003)$ on longitudinal distance from threshold (mean=1046 ft, standard deviation, $\sigma=439 \mathrm{ft}$ ) compared to their absence (mean $=803 \mathrm{ft}, \sigma=356 \mathrm{ft}$ ). Display concept and the interaction between display concept and TDZ/CL lights were not significant ( $\mathrm{p}>0.05$ ) for longitudinal T/D distance (mean=928ft, $\sigma=417 \mathrm{ft}$ ).

There were no significant ( $\mathrm{p}>0.05)$ effects for the main factors (display concept, TDZ/CL lights) or their interaction in the lateral T/D position from centerline (mean $=-0.18 \mathrm{ft}, \sigma=17.5 \mathrm{ft}$ ) or sink rate (mean $=-7.3 \mathrm{ft} / \mathrm{sec}, \sigma=2.8 \mathrm{ft} / \mathrm{sec}$ ).

EFVS runs: No significant ( $\mathrm{p}>0.05$ ) OTW visibility level effects, TDZ/CL light effects, or second-order interaction effects were found on longitudinal T/D position (mean=984 ft, $\sigma=381 \mathrm{ft}$ ), lateral T/D position (mean= $-0.49 \mathrm{ft}, \sigma=14.5$ $\mathrm{ft}$ ), or T/D sink rate (mean $=-7.2 \mathrm{ft} / \mathrm{sec}, \sigma=2.9 \mathrm{ft} / \mathrm{sec}$ ) for the EFVS display concepts.

SVS HUD runs: ANOVA analyses revealed significant OTW visibility differences $(\mathrm{F}(1,33)=4.43, \mathrm{p}=0.043)$ on longitudinal distance from threshold between the $1400 \mathrm{ft}$ RVR level (mean=1012 ft, $\sigma=406 \mathrm{ft}$ ) and the $1000 \mathrm{ft}$ RVR level (mean $=757 \mathrm{ft}, \sigma=347 \mathrm{ft}$ ). TDZ/CL lights and the interaction between OTW visibility and TDZ/CL lights were not significant $(\mathrm{p}>0.05)$ for this measure (mean $=895 \mathrm{ft}, \sigma=397 \mathrm{ft}$ ).

There were also no significant ( $>0.05$ ) effects for the main factors (OTW visibility, TDZ/CL lights) or their interaction in the lateral T/D position from centerline (mean $=0.25 \mathrm{ft}, \sigma=17.0 \mathrm{ft}$ ) or sink rate (mean= $-7.0 \mathrm{ft} / \mathrm{sec}, \sigma=2.7 \mathrm{ft} / \mathrm{sec}$ ).

SVS HDD runs: There were no significant ( $\mathrm{p}>0.05$ ) effects for the main factors (OTW visibility, TDZ/CL lights) or their interaction in the longitudinal T/D position (mean $=860 \mathrm{ft}, \sigma=428 \mathrm{ft}$ ), lateral T/D position from centerline (mean $=$ $0.18 \mathrm{ft}, \sigma=17.5 \mathrm{ft}$ ) or T/D sink rate (mean $=-7.3 \mathrm{ft} / \mathrm{sec}, \sigma=2.8 \mathrm{ft} / \mathrm{sec}$ ) measures.

\subsubsection{Objective Landing Standards Analysis}

Existing AC120-28D ${ }^{19}$ (Appendix 3) performance-based "auto-land" standards for T/D longitudinal position, lateral position from centerline, and sink rate were applied in the objective landing data analysis. Specifically, the standards require no longitudinal touchdown earlier than a point on the runway $200 \mathrm{ft}$ from the threshold or beyond $2700 \mathrm{ft}$ from the threshold, no lateral touchdown with the outboard landing gear more than $70 \mathrm{ft}$ from the runway centerline, and no touchdown sinkrate greater than -10 feet/second to a probability of $1 \times 10^{-6}$. These standards pertain to the general concept of low-visibility approach and landings, but were not written specifically for operations with advanced vision systems such as SVS/EFVS.

This experiment used an aim point located $1000 \mathrm{ft}$ from runway threshold. For the simulated 757 aircraft, the outboard landing gear would be $70 \mathrm{ft}$ from the centerline when the fuselage is at $58 \mathrm{ft}$ lateral deviation from centerline, assuming no crab angle at touchdown.

In Figure 4, the touchdown data are shown, broken out by display concept and TDZ/CL light configurations for the 1400 RVR OTW and $150 \mathrm{ft} \mathrm{DH}$ crew runs. Included on this plot is the touchdown aim point $(0 \mathrm{ft}$ lateral distance, $1000 \mathrm{ft}$ longitudinal distance) indicated by the axes origin.

Visual inspection of the data shows that 1) all display concepts were within the lateral deviation from centerline touchdown criteria (within $\pm 58 \mathrm{ft}$ lateral distance) and 2) all the HUD runs (i.e., Baseline, SVS and EFVS) were within the longitudinal position touchdown criteria (between $200 \mathrm{ft}$ to $2700 \mathrm{ft}$ longitudinal distance).

Four landings were outside of the "acceptable" performance criteria for longitudinal touchdown position - two baseline HDD in 1400 RVR (one as short $53 \mathrm{ft}$ ) with TDZ and CL and two SVS HDD in 1400 RVR without TDZ and CL lights (one as short as $26.8 \mathrm{ft}$ ). As mentioned before, one pilot landed $50 \mathrm{ft}$ short of the threshold while flying the SVS HDD configuration in $1800 \mathrm{RVR}$ with TDZ and CL lights. In all of these five cases, the pilots were essentially flying visually, without reference to HUD information or SVS/EFVS imagery.

None of the concepts tested met the $10^{-6}$ probability of occurrence auto-land criteria for T/D longitudinal position, lateral position from centerline, or sink rate. 


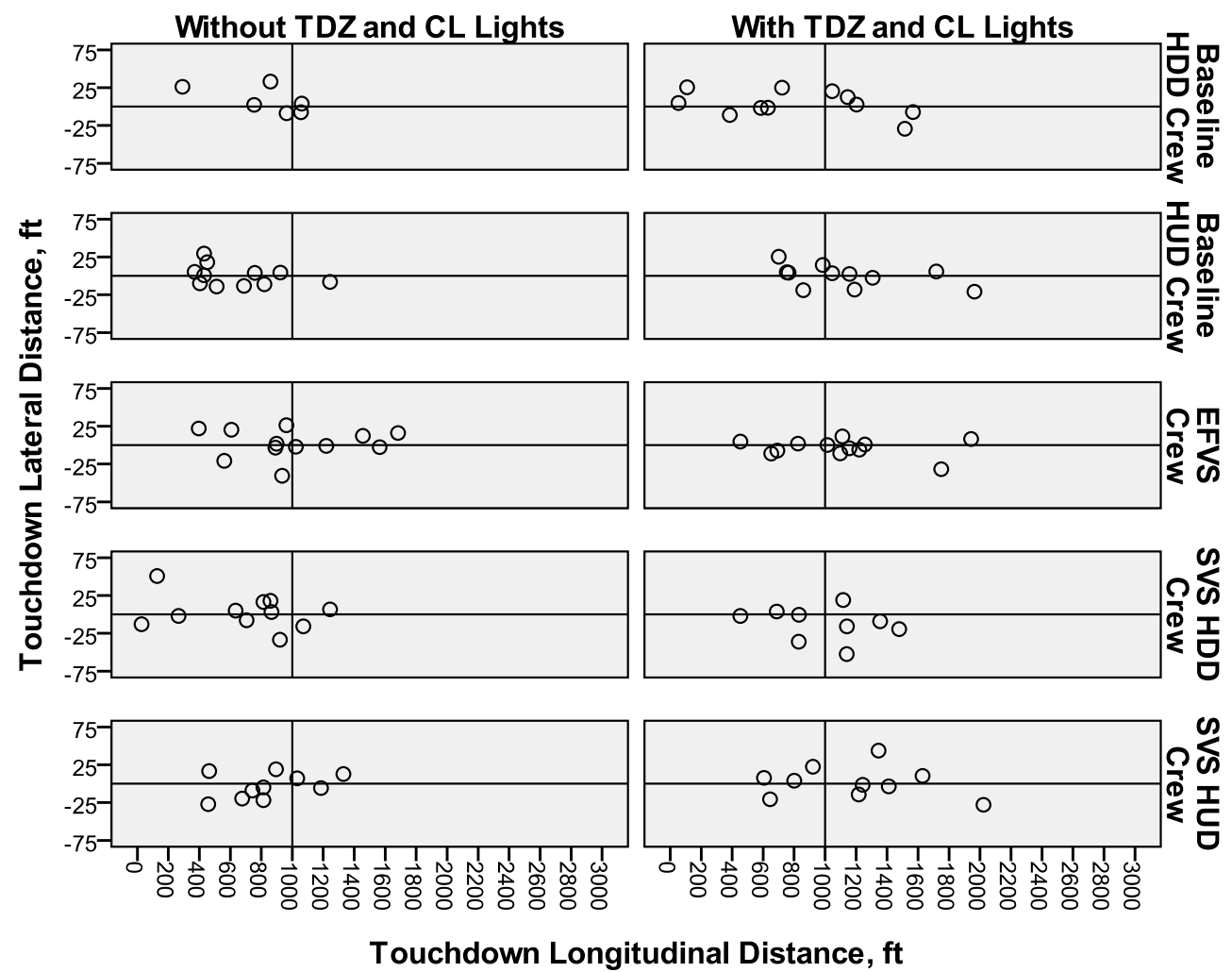

Figure 4. Touchdown Footprint for Crew Display Concepts in 1400 RVR OTW and $150 \mathrm{ft} \mathrm{DH}$

\subsection{Landing Performance Discussion}

Lateral deviation from centerline touchdown performance was excellent for all concepts tested.

Expanding the EFVS visual segment from DH to the runway in visibilities as low as 1000 RVR appears to have had no negative consequences on approach/landing performance. First, and probably most important, no go-arounds were performed while using an EFVS. Second, approaches using the EFVS concept resulted in excellent longitudinal (mean= $984 \mathrm{ft}, \sigma=381 \mathrm{ft}$ ) and lateral (mean $=-0.49 \mathrm{ft}, \sigma=14.5 \mathrm{ft}$ ) touchdown performance regardless of OTW visibility level or if there were TDZ/CL lights or not. It is also interesting to note that the mean longitudinal distance from aim point was only $12 \mathrm{ft}$ for this test when using the EFVS concept. Past NASA research ${ }^{16}$ flying similar EFVS approach operations resulted in a mean longitudinal distance of $708 \mathrm{ft}$ past the aim point. Applying recommendations from that experiment (automatic throttle retard to idle at $35 \mathrm{ft}$, providing pilots touchdown performance feedback during training and training each pilot to a common "desired" touchdown performance proficiency level) appears to have led to improvements in longitudinal T/D performance.

When using the SVS HUD concept, longitudinal T/D performance and the ability to complete a landing were affected by the OTW visibility. As visibility decreased from $1400 \mathrm{ft}$ to $1000 \mathrm{ft}$ RVR, the number of go-arounds increased significantly - to where almost one-third of the approaches resulted in TOGA - and the mean distance from the touchdown aim point increased by $255 \mathrm{ft}$.

Longitudinal T/D performance using the SVS HDD concept was influenced by the presence of TDZ/CL lights. The EPs were able to land within 24 feet (on average) of the aim point when the TDZ/CL lights were on but only within $119 \mathrm{ft}$ (on average) when they were off. Also, as visibility decreased from 1800 to 1400 , the number of go-arounds when using the SVS HDD concept increased by 13\%. But in comparison to flying without SVS in these same conditions (i.e., flying the Baseline HDD in 1400 RVR), SVS provided a notable reduction in TOGAs (7 TOGAs vs. 4) likely by providing an aided search for the pilots (i.e., they knew where to look for the runway and may have had better awareness of the situation approaching the $\mathrm{DH})$. 
The presence of TDZ/CL lights had a significant effect on longitudinal T/D position past threshold, but not on lateral deviation from centerline or T/D sink rate. With TDZ/CL lights, the mean longitudinal distance from threshold (collapsed across display concepts, mean $=1046 \mathrm{ft}$ ) was much closer to the (1000 ft from threshold) aim point than when there were none (mean=803 ft). Also, in $1400 \mathrm{ft}$ OTW RVR, pilots were almost twice as likely to complete a Baseline HDD approach to a landing if TDZ/CL lights were present.

The T/D sink rate data shows significantly higher values across all conditions than expected. Since none of the display or lighting conditions seemingly affect the sink rate performance, the probable cause for this disparity, despite pre-test training, is the lack of simulator motion and the unfamiliar handling characteristics of a sidestick-controlled B-757.

\subsection{Workload}

Workload was assessed after each experimental run, independently for the PF and PNF, using the Air Force Flight Technical Center Workload Estimate Technique. ${ }^{18}$ Workload ratings while using SEVS concepts were evaluated by conducting ANOVA analyses for the factors of display concept (Baseline HUD, SVS HUD, EFVS, Baseline HDD, and SVS HDD) and TDZ/CL lights (on, off) for the fixed $1400 \mathrm{RVR}$ visibility/150 ft DH. Workload ratings while using SVS and EFVS were evaluated by conducting separate ANOVAs across OTW visibility and TDZ/CL lights. When necessary, Student-Newman-Keuls (SNK) post-hoc tests ( $\alpha$ set at 0.05 ) were performed.

\subsubsection{SEVS Workload Ratings}

For the fixed $1400 \mathrm{OTW} R \mathrm{RVR} / 150 \mathrm{ft} \mathrm{DH}$, ANOVAs revealed significant display concept differences $(\mathrm{F}(4,103)=3.39$, $\mathrm{p}=0.012$ ) for the PF workload ratings, but not for the PNF workload ratings (mean rating=2.7). Post-hoc tests showed two overlapping subsets for PF workload ratings: 1) EFVS (mean=2.9), SVS HUD (mean=3.1), Baseline HUD (mean=3.3) and 2) SVS HUD, Baseline HUD, SVS HDD (mean=3.6), Baseline HDD (mean=3.7). The PFs rated their workload as "being moderate, easily managed and having considerable spare time" when using the EFVS and that the EFVS required significantly less workload than when using the Baseline or SVS HDD concepts (rated as "being challenging but manageable and with adequate time available"). There were no appreciable workload differences between: 1) the three HUD concepts (EFVS, SVS, and Baseline) or 2) the Baseline and SVS HUD concepts and the Baseline and SVS HDD concepts. There were also no significant ( $p>0.05$ ) differences among the TDZ/CL lights factor or the second-order interaction between display concept and TDZ/CL lights for either the PF or PNF workload ratings.

\subsection{2 $\quad$ EFVS Workload Ratings}

ANOVAs revealed no significant differences for OTW visibility, TDZ/CL lights, or the interaction between these two factors for the EFVS PF (mean=2.8) or PNF (mean=2.6) workload ratings. On average, both the PFs and PNFs rated their workload as being "moderate, easily managed and having considerable spare time" while using the EFVS display concept on approach through landing in visibilities as low as 1000 RVR.

\subsubsection{SVS Workload Ratings}

ANOVAs for the SVS HUD and SVS HDD concepts revealed no significant differences for OTW visibility, TDZ/CL lights, or the interaction between these two factors for the SVS HUD PF (mean=3.2) and PNF (mean=2.8) workload ratings or the SVS HDD PF (mean=3.4) and PNF (mean=2.6) workload ratings. On average, both the PFs and PNFs rated their workload as being "moderate, easily managed and having considerable spare time" while using the SVS display concepts on approach through landing in visibilities as low as 1000 RVR for the HUD and 1400 RVR for the HDD.

\subsection{Crew Display Concept Preferences}

The PF and PNF were independently asked to rank order the display concepts (Baseline HDD, SVS HDD, Baseline HUD, SVS HUD, and EFVS) from most preferred display (rank=1) to least preferred display (rank=5) for flying with in low-visibility conditions. The pilots ranked their low-visibility operations display concept preferences as follows: 1) EFVS (most preferred), 2) SV HUD, 3) Baseline HUD, 4) SVS HDD, and 5) Baseline HDD (least preferred). Friedman's test statistic showed there were significant differences among the displays for both the $\mathrm{PF}\left(\chi^{2}(4)=31.145\right.$, $\mathrm{p}<0.001)$ and $\operatorname{PNF}\left(\chi^{2}(4)=41.818, \mathrm{p}<0.001\right)$ preference rankings. 


\section{CONCLUSIONS}

A fixed-base pilot-in-the-loop simulation test was conducted at NASA Langley Research Center which evaluated the use of synthetic vision systems/enhanced flight vision systems (SVS/EFVS) in Next Generation Air Transportation System low visibility approach/landing operations at Chicago O'Hare environment. Various scenarios tested the potential for EFVS for operations in visibility as low as $1000 \mathrm{ft}$ runway visibility range (RVR) and SVS to enable lower decision heights or visibilities than can currently be flown today.

Objective results indicate that expanding the EFVS visual segment from decision height (DH) to the runway in visibilities as low as $1000 \mathrm{ft}$ RVR appears to be viable as longitudinal and lateral touchdown performance were excellent. Perhaps more important than the landing performance results is that the go-around rate was $0 \%$ when flying the EFVS concept, regardless of the out-the-window (OTW) visibility level (1000 or $1400 \mathrm{ft} R \mathrm{RR})$ or if there were touchdown zone/center line (TDZ/CL) lights present or not. The enhanced flight visibility was held at approximately $2400 \mathrm{ft}$. Subjective results also supported the EFVS visual segment expansion to the runway. This concept was rated as having less workload and was ranked as the crew's preferred display concept (over the Baseline and SVS concepts tested) to fly with in low-visibility conditions.

Objective and subjective results also lend support for using SVS (head-up) to enable lower decision heights and/or lower OTW visibility than are currently flown in today's National Airspace System. Regardless of OTW visibility level or the absence/presence of TDZ/CL lights, all SVS concepts evaluated easily met the desired lateral touchdown criteria defined for this test. However, OTW visibility effects were found for go-around rate with the SVS HUD and SVS HDD concepts and longitudinal touchdown performance with the SVS HUD concept. SVS HUD operations in visibilities as low as $1400 \mathrm{RVR}$ appear possible, but operations in $1000 \mathrm{ft}$ RVR appear to require less intrusive implementations of the SVS imagery on the HUD to enable easier acquisition of the required visual landing cues at DH. SVS HDD operations in $1800 \mathrm{ft}$ RVR with a $150 \mathrm{ft}$ DH appear promising if TDZ/CL lights are present. Further study, including analysis of eye gaze data obtained in this experiment, is needed before conclusions can be drawn.

In general, having TDZ/CL lights appears to have aided the pilots in landing closer to the touchdown aim point (1000 ft past the runway threshold).

Future research should include motion-based simulation testing for the SVS HUD and HDD concepts to assess its impact on approach and landing performance, especially in sink rate control on touchdown.

\section{ACKNOWLEDGEMENTS}

This work was jointly sponsored by NASA's Aviation Safety Program (AvSP), Vehicle Systems Safety Technologies project (especially, Dr. Steve Young, Project Scientist) and the FAA Human Factors R\&D Project for NextGen, led by Dr. Tom McCloy and Mr. Dan Herschler. Programmatic support and technical advice from these groups was gratefully appreciated.

\section{REFERENCES}

[1] Joint Planning and Development Office. (2008). Next generation air transportation system integrated plan: a functional outline. Washington, DC: Author.

[2] Federal Aviation Administration. (n.d.). Instrument Flight Procedures (IFP) Inventory Summary. Retrieved February 28, 2011, from http://www.faa.gov/air_traffic/flight_info/aeronav/ifpinventorysummary.

[3] Arthur, J. J., III, Prinzel, L. J., III, Kramer, L. J., Bailey, R. E., and Parrish, R. V. (2003). CFIT prevention using synthetic vision. Proceedings of SPIE, Enhanced and Synthetic Vision 2003, 5018, 146-157.

[4] Schiefele, J., Howland, D., Maris, J., Pschierer, C., Wipplinger, P., and Meuter, M. (2005) Human factors flight trial analysis for 3D SVS: Part II. Proceedings of SPIE, Enhanced and Synthetic Vision 2005, 5802, 195-206.

[5] Schnell, T., Theunissen, E., and Rademaker, R. (2005). Human Factors Test \& Evaluation of an Integrated Synthetic Vision and Sensor-Based Flight Display System for Commercial and Military Applications. Paper presented at the NATO Research and Technology Organization, Human Factors and Medicine panel workshop entitled "Toward Recommended Methods for Testing and Evaluation of EV and E/SV-Based Visionic Devices", Williamsburg, VA, USA, 26-27 April 2005.

[6] Kramer, L. J., Prinzel, L. J., III, Bailey, R. E., and Arthur, J. J., III (2003). Synthetic vision enhances situation awareness and RNP capabilities for terrain-challenged approaches. Proceedings of the American Institute of 
Aeronautics and Astronautics Third Aviation Technology, Integration, and Operations Technical Forum, AIAA 2003-6814, 1-11.

[7] French, G. and Schnell, T. (2003). Terrain awareness \& pathway guidance for head-up displays (TAPGUIDE): a simulator study of pilot performance. Proceedings of 22nd IEEE/AIAA Digital Avionics Systems Conference, 2, pp. 9.C.4 - 9.1-7.

[8] Lemos, K. and Schnell, T. (2003). Synthetic vision systems: human performance assessment of the influence of terrain density and texture. Proceedings of 22nd IEEE/AIAA Digital Avionics Systems Conference, 2, pp. 9.E.3 - 9110.

[9] Schnell T., Kwon, Y., Merchant, S., Etherington, T., and Vogl, T. (2004). Improved flight technical performance in flight decks equipped with synthetic vision information system displays. International Journal of Aviation Psychology, 4, 79-102.

[10] Alexander, A. L., Wickens, C. D., and Hardy, T. J. (2005). Synthetic vision systems: the effects of guidance symbology, display size, and field of view. Human Factors: The Journal of the Human Factors and Ergonomics Society, 47 (No. 4), 693-707.

[11] Kramer, L. J., Arthur, J. J., III, Bailey, R. E., and Prinzel, L. J., III. (2005). Flight testing an integrated synthetic vision system. Proceedings of SPIE, Enhanced and Synthetic Vision 2005, 5802, 1-12.

[12] Kramer, L. J., Williams, S. P., and Bailey, R. E. (2008). Simulation evaluation of synthetic vision as an enabling technology for equivalent visual operations. Proceedings of SPIE, Enhanced and Synthetic Vision Conference 2008, 6957, 1-15.

[13] Minimum Aviation System Performance Standards (MASPS) for Enhanced Vision Systems, Synthetic Vision Systems, Combined Vision Systems and Enhanced Flight Vision Systems. RTCA/DO-315, RTCA Inc. Washington, DC. Dec 2008.

[14] Enhanced Flight Vision Systems. FAA/AC 90-106, Washington, DC: Author. June 2010.

[15] Minimum Aviation System Performance Standards (MASPS) for Enhanced Vision Systems, Synthetic Vision Systems, Combined Vision Systems and Enhanced Flight Vision Systems. RTCA/DO-315A, RTCA Inc. Washington, DC. Sept 2010.

[16] Bailey, R. E., Kramer, L. J., and Williams, S. P. (2010). Enhanced vision for all-weather operations under NextGen. Proceedings of SPIE Enhanced and Synthetic Vision Conference 2010, 7689, pp. 768903-1-768903-18.

[17] Corps, S. G. (1986). Airbus A320 side stick and fly by wire - an update. 5th SAE Aerospace Behavioral Engineering Technology Conference, Paper No. 861801.

[18] Ames, Lawrence L. \& George, Edward J. (1993). Revision and verification of a seven-point workload estimation scale. Air Force Flight Technical Center: AFFTC-TIM-93-01.

[19] Federal Aviation Administration Advisory Circular: Criteria for Approval of Category III Weather Minima for Takeoff, Landing, and Rollout, AC-120-28D, Dated July 13, 1999.

[20] Vidulich, M. A. and Hughes, E. R. (1991). Testing a subjective metric of situation awareness. Proceedings of the Human Factors \& Ergonomics Society, 35th Annual Meeting, 1307-1311. 